Original title / titulo original: The Secret of the Knot:

Khipu No. 936 from the Maiman Collection

Author(s)/ autor(es):

Bat-ami Artzi

Published originally as/ Publicado originalmente en:

Estudios Latinoamericanos, 30 (2010), pp. 187-214

DOI: https://doi.org/10.36447/Estudios2010.v30.art8

Estudios Latinoamericanos is a journal published by the Polish Society for Latin American Studies (Polskie Towarzystwo Studiów Latynoamerykanistycznych).

The Polish Society for Latin American Studies is scholarly organization established to facilitate research on Latin America and to encourage and promote scientific and cultural cooperation between Poland and Latin America.

Estudios Latinoamericanos, revista publicada por la Sociedad Polaca de Estudios Latinoamericanos (Polskie Towarzystwo Studiów Latynoamerykanistycznych).

Sociedad Polaca de Estudios Latinoamericanos es una asociación científica fundada con el fin de desarrollar investigaciones científicas sobre América Latina y participar en la cooperación científica y cultural entre las sociedades de Polonia y América Latina. 


\title{
The Secret of the Knot: Khipu No. 936 from the Maiman Collection
}

\author{
Bat-ami Artzi
}

Tn the 1950s a private collector from Lima bought a group of 18 khipus, which 1 were found in the area of Trujillo. The director of the Maiman Collection, Alfredo Rosenzweig, purchased two khipus from this group (MC 936, MC 935) from the daughter of the aforementioned private collector. Today the other samples are scattered around the world in the possession of the descendants of the first owner. Two khipus from this group are also currently in Israel; other samples are located in Peru, Brazil, the United States, and France.

According to the son of their first owner, ethnologist and epigrapher Thomas Barthel studied this group of khipus in 1951 and in 1971, but there is no summary of his research. Ari Zighelboim studied this khipu and seven others from this group, and examined photographs of another four but he did not publish his findings either. From the information Zighelboim shared with me, it seems that all those khipus come from the region of Trujillo. They all share similarities in materials, colors, types of knots and cord twisting (Ari Zighelboim, personal communication 2008).

A preliminary description of this khipu was published in the collection's textiles catalogue, Weaving for the Afterlife - Peruvian Textiles from the Maiman Collection (Figure 1), and it was ascribed to the Inca era (Makowski et al. 2006). 


\section{The Method to Describe a Khipu}

Khipu description is the foundation of khipu research. The description of one khipu sample can be shared with all who take an interest in this device, for comparison of different samples, and for identifying possible connections between them. The preliminary aim of my investigation was to describe khipu no. 936 from the Maiman Collection so it could be published and would be part of the growing information of the khipu study.

Throughout my investigation of this khipu I have enjoyed the luxury of learning from the experiences of my predecessors. There are two major projects to create a database of khipus descriptions; the first was carried out by Marcia and Robert Ascher and the second by Gary Urton and colleagues.

In 1970, Marcia and Robert Ascher started to develop a database for khipus, which later became a khipu data book. They developed a method for describing khipu. The couple traveled across three continents and used this method for describing more then 200 khipus.

The format of the Ascher description is divided into four parts, the first part identifies the khipu via its current tag in the museum or collection it belongs to. The second part describes the main cord, starting from the looped end and continuing with the description of the location of all the secondary cords attached to the main cord, and also measures the distance from one cord to another. This description mentions each type of cord (top or secondary), and labels it with a number.

The third part describes each cord in a table, according to the order in which it appears in the khipu. The first column deals with the cord type (secondary, subsidiary or top cord) and its serial number. The description of the subsidiary cord is located below the line describing its parent cord. The second column contains the number and type of each knot and its placement on the cord. The third column describes the length of the cord and the form of its end. The fourth column contains a color code, and a code for describing color combinations. The color codes comply with the ISCC-NBS (the Inter-Society Color Council-National Bureau). The fifth column contains the estimated numerical value of the knots. The sixth column refers to subsidiary cords if there are any, as well as their number and placement on the cord.

The fourth part of the description contains specific observations about the khipu given by its owner, such as information about the khipu's origin, and additional notes recorded by the Aschers in examining the link between the specific sample and other khipu samples. This part also describes special features, such as the color pattern or inner logic of the khipu in question (Ascher and Ascher 1978). 


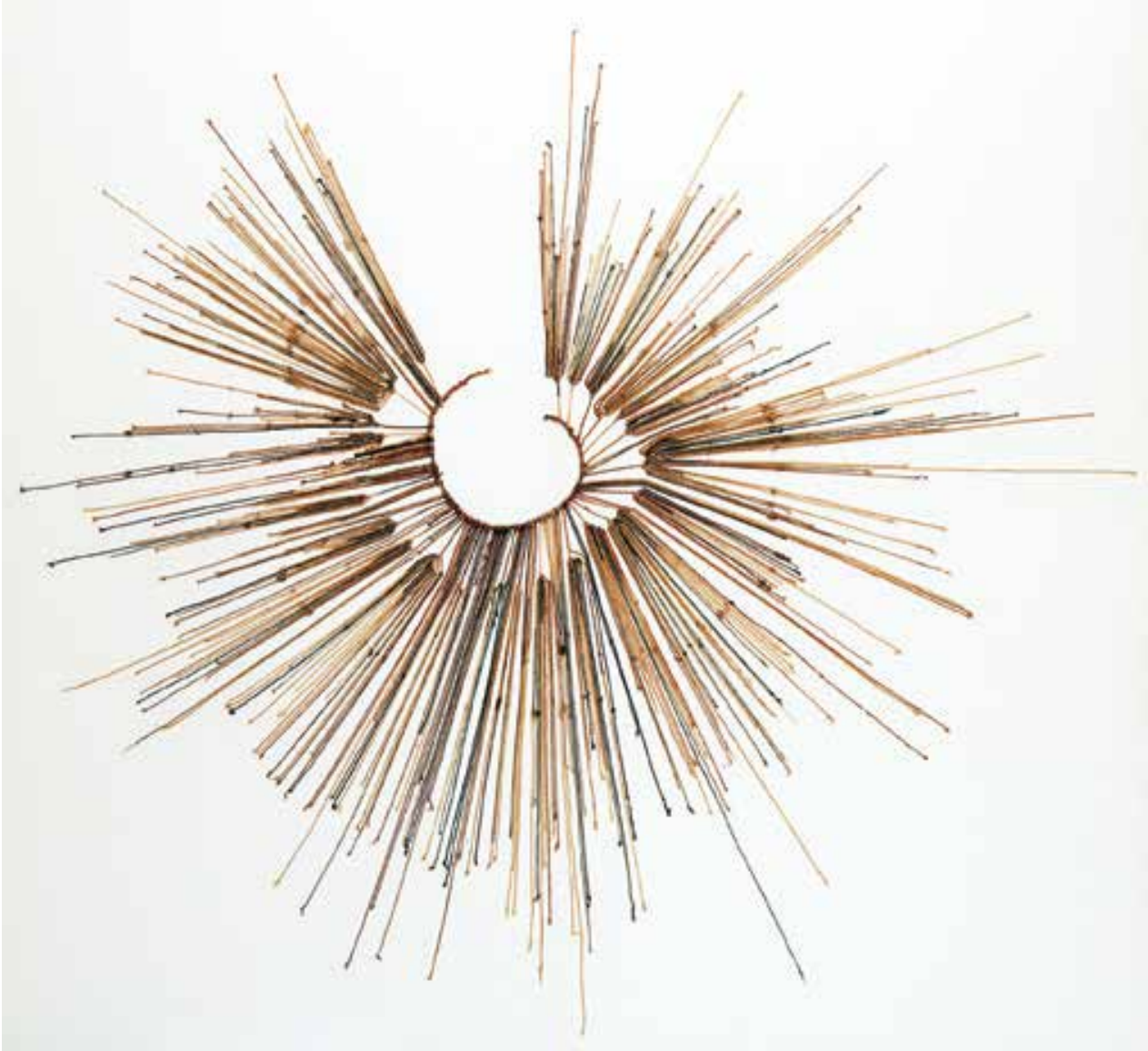

Figure 1. Khipu no. 936, Maiman Collection (from the textile catalogue of the collection: Makowski et al. 2006).

In 2002, another project, The Khipu Database Project, was developed and conducted by Gary Urton and funded by the National Science Foundation and Harvard University (Urton and Brezine 2009).

The database contains descriptions of khipus which were not described by the Aschers, along with additional information about the khipus the Aschers had previously described. Urton accepted the Aschers' method for describing the khipu. However, he believed it was incomplete, so he added the missing components:

- Information about materials used to manufacture the khipu;

- Additional information about the main cord, including spinning, plying and wrapping;

- The spinning and plying of all cords of the khipu; 
- The way cords are attached to one another: backwards or forwards;

- $\quad$ The form of the knot: $\mathrm{Z}$ or S (Urton 2003).

\section{My Method for Describing Khipu No. 936 from the Maiman Collection}

In my investigation of khipu no. 936 from the Maiman Collection I adopted the Aschers' and Urton's methods, but I also made some changes in the description table. These changes are based on my belief that certain special khipus require a more elaborate treatment, depending on the specific components contained within the khipu. I was able to customize the table because I was dealing with only one khipu, and not a large group of them.

I based the table on the work of the Aschers and Urton, and then modified it to fit this specific khipu; I did not want to impose a pre-prepared table on the sample. While describing the khipu, the table had to be modified when I came across a component that was not included as a category in the table template. This is especially true in the case of subsidiary cords, which are one of the most dominant features of this khipu, therefore I modified the method of cords labeling. In addition, in my method I added a column that records the side on which subsidiary cords are attached to the parent cords, either to the right or to the left of the cord (for full information on my method of describing see Appendix no. 1).

It is important to mention that khipu no. 936 is quilted and framed for conservation reasons. This prevented me from touching the khipu and from accessing information regarding the other side of the khipu. For this reason, one component, the knot form S or Z, which was referred by Urton was not recorded by me. I could not record this information for all the knots; in many cases, the axis of the knot was located on the inaccessible side of the khipu, and therefore could not be examined. In the end, I chose not to record this feature at all, rather than record it partially.

\section{Khipu No. 936 from the Maiman Collection}

This khipu is made of cotton; there is no evidence of animal hair use. There are a total of 358 cords in this khipu, including a few cords which are actually cord remnants. There are only secondary cords and subsidiary cords in this khipu; there is no evidence of top cords. The cords appear on four levels: secondary cords, first-level subsidiary cords, second-level subsidiary cords and thirdlevel subsidiary cords. Most of the khipu's cords are subsidiary cords. The cords are distributed as follows:

- secondary cords - 95;

- first-level subsidiaries - 165; 


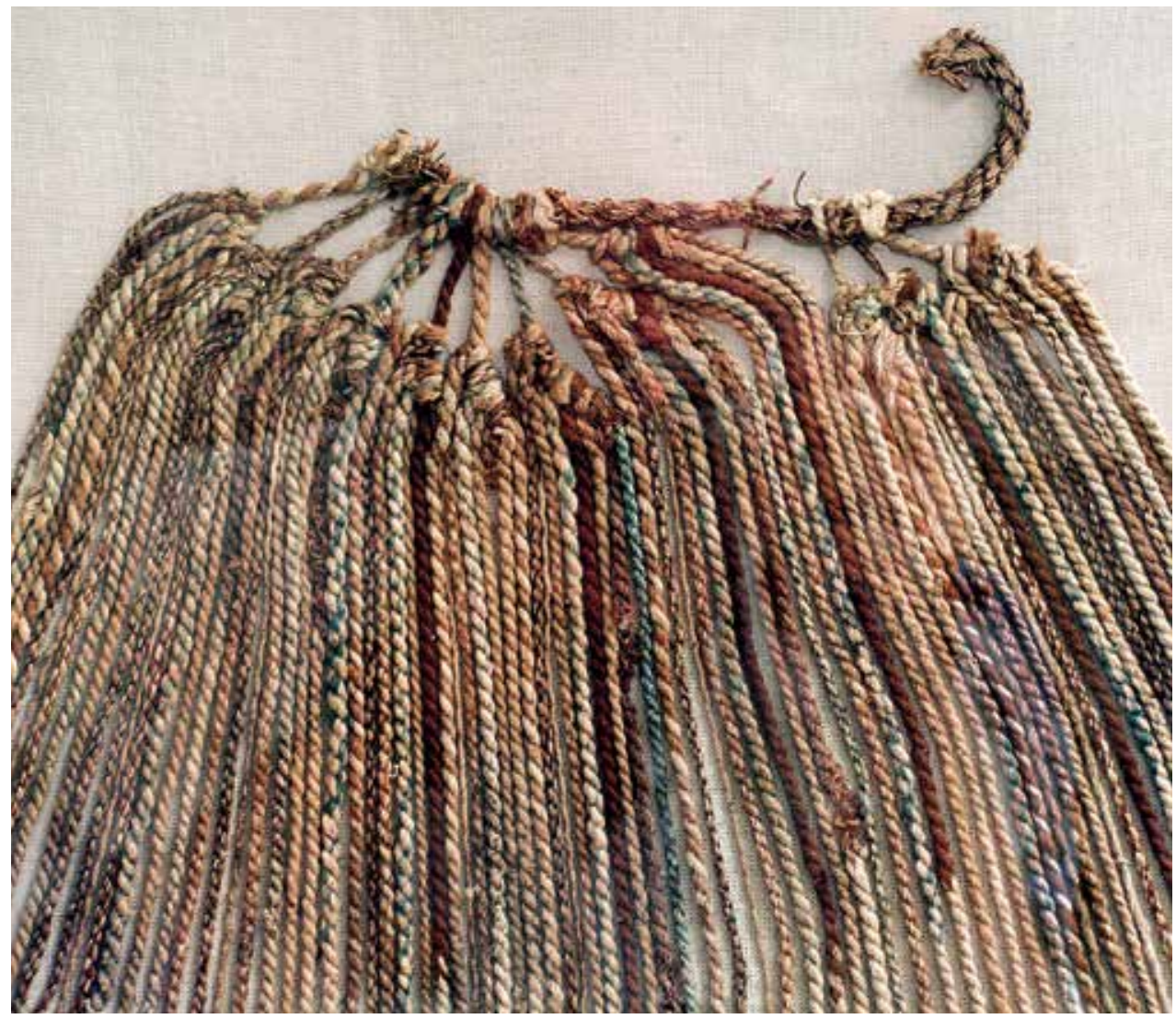

Figure 2. The upper part of khipu no. 11 (courtesy of the owner).

- second-level subsidiaries - 85;

- third-level subsidiaries -9 .

The secondary cords in this khipu constitute only 26 percent of the all khipu's cords; this is a very remarkable feature. There are 24 secondary cords containing subsidiary cords. The remaining 71 secondary cords do not have any subsidiary cords.

The cluster which has the largest number of subsidiary cords is cluster no. 90, containing 30 subsidiary cords in all. The cluster with the second largest number is cluster no. 9 , with 26 subsidiary cords.

The secondary cords are located on the main cord, with varying spaces between, from 0.3 to $3.0 \mathrm{~cm}$; the average space between secondary cords is $0.8 \mathrm{~cm}$. In cases where there is no space between secondary cords, there are two to eight cords pressed together. The secondary cords are not divided equally into groups; neither did I find any logic of inner division. 


\section{The Attachment Point of the Cords}

The distance between the point of attachment of subsidiary cords to secondary cords, and the point of attachment of secondary cords to the main cord, ranges from 0.2 to $12.4 \mathrm{~cm}$, with an average of $8.3 \mathrm{~cm}$. The distance between the attachment points of the second-level subsidiary cords, to the attachment points of the first-level subsidiary cords, ranges from 0.5 to $10.3 \mathrm{~cm}$, with an average of $1.8 \mathrm{~cm}$. The distance between the attachment points of the third-level subsidiary cords to the attachment points of the second-level subsidiary cords ranges from 0.8 to $2.5 \mathrm{~cm}$, with an average of $1.21 \mathrm{~cm}$. In cases in which a cord includes both subsidiary cords and knots, the attachment of the subsidiary cord is above the knots. This applies to all cord levels. The distance between the attachment point of the subsidiary cord, and the highest knot, averages $11 \mathrm{~cm}$, more or less the equivalent of the width of a hand. It is interesting to note that in the first half of the khipu this distance ranges from 12 to $16.5 \mathrm{~cm}$, while in the second half of the khipu, the distance ranges from 5 to $10.5 \mathrm{~cm}$.

\section{The Length of the Cords}

The length of the cords (excluding cords with ruptured ends) ranges from 18 to $84 \mathrm{~cm}$, with an average of $44 \mathrm{~cm}$. I tried to find commonalities among all the long cords, and analyze whether they served as some sort of an inner division of the khipu. The longest cords, from $60 \mathrm{~cm}$ and up in the second half of the khipu, are secondary cords with no subsidiary cords. In the khipu's first half there are eight long cords, some of which include subsidiary cords.

\section{The Direction of the Cords' Attachment}

Concerning the attachment direction of the subsidiary cord (to the right or to the left), the left-side attachments (68 percent) dominate the right-side attachments (32 percent). In half of the cases of right-side subsidiary cord attachments, they are subsidiary cords of the third level. It is interesting to note that all of the cords in cluster no. 28 (the midpoint of the khipu in its current state) are attached to the right side.

\section{The Method of the Cords' Attachment}

Concerning the method of the attachment of cords to one another (recto or verso), I discovered that there is a close connection between this component and the direction of attachment: the verso form appears only in subsidiary cords that were attached to the right side and the recto form appears only in subsidiary 
cords that were attached to the left side. It might have been done in this fashion simply for reasons specific to the creator of the khipu in the creation process. But at the same time, those two components and their combination might have encoded some sort of information. The answer to this question might be clarified by studying the connection between these two components in other samples, which could reveal whether this correlation is consistent with other samples, or whether it is a unique characteristic of this khipu.

Recto attachments make up 68 percent of the cases, while verso attachments make up only 32 percent. As we have seen, the correlation between method of attachment and direction of attachment is 100 percent, so the percentages remain the same. Similarly, the other observations made regarding the distribution of the direction of attachments also apply to the distribution of the different methods of attachment.

\section{Spinning and Plying of the Cords}

In the case of the spinning and plying of the cords, almost 100 percent of the cords were made in the $S$ form, with the exception of one cord, no. 90-5-1-1, which was made in the $\mathrm{Z}$ form (there were also a few cases of unraveled cords, which appear to be $\mathrm{Z}$ form, and likely used to form the base of an $\mathrm{S}$ cord).

\section{The Color Component}

The colors of the cords are natural cotton colors, except blue which is dyed (Makowski et al. 2006). I identified 17 different colors and hues in khipu no. 936. The colors were integrated in three ways: layered, twisted and spotted. One of the most striking characteristics about this khipu is the rich use and variation of color; only 25 percent of the cords ( 91 cords) contain one single color. These single-color cords appear in white, brown hues, blue hues or khaki.

The use of color combinations is as follows:

- layered cords (including the use of the two other combination methods)

- 105 cords;

- twisted cords - 82 cords;

- spotted cords - 70 cords.

Regarding the layered cords, there are ten ruptured cords and due to their damaged condition, it is not clear whether they are layered; these ten cords are not included in the number listed above. 


\section{The Use of the Layered Method}

Layered cords may contain within them the other two types of color combinations: twisted and spotted. There are 41 layered cords that do not contain the other color combinations on any layer. Layered cords contain up to five layers of colors and color combinations. There are 88 cords that contain two layers each, 15 cords that contain three layers, two cords with four layers and one cord which contains five layers.

The length of the first layer ranges from 4 to $26.5 \mathrm{~cm}$, averaging $9.8 \mathrm{~cm}$. The length of the second layer ranges from 3.5 to $65.5 \mathrm{~cm}$, averaging $31.6 \mathrm{~cm}$. The length of the third layer ranges from 7 to $42.5 \mathrm{~cm}$, averaging $32.4 \mathrm{~cm}$. In the two cords with four layers, the lengths of the fourth layers are $10 \mathrm{~cm}$ and $27 \mathrm{~cm}$ respectively, and in the five-layer cord, the length of the fifth layer is $20 \mathrm{~cm}$.

In the majority of the layered cords, the lowest layer (furthest away from the main cord) is the longest. The ratio between the second and the first layers in the layered cords averages $3 \mathrm{~cm}$. The ratio between the third and second layers of the layered cords averages $2.77 \mathrm{~cm}$. In most of the cases, the lowest layer is composed of one color. However, 15 cords do contain color combinations at the lowest layer. Interestingly, these 15 cords are all secondary cords.

White is found at the lowest level in 74 percent of the layered cords. There are only two cases in which the color of the cord changes in the middle of a knot or knot cluster: in cords 25-0-0-0 and 28-0-0-0 (the midpoint of the khipu in its current state).

\section{The Use of the Twisted Method}

In most cases, two colors are twisted together, though a few cases show three twisted colors. With the exception of three cords, all twisted cords in this khipu contain the color white as one of the colors that are twisted.

\section{The Use of the Spotted Method}

The majority of spotted cords contain two colors. However, there are a few examples of three or four colors being integrated in the spotted method. Except in two cases (cords no. 3-0-0-0 and 9-0-0-0), all spotted combinations contain the color white. In those two exceptional cases, the white is present in the lower layer of the cord.

There are around 8 million possible combinations which can be produced from the 17 colors and hues, and the three color-combination methods, found in this khipu. However, only 88 of these possibilities are exploited (this amount might be different, depending on the definitions of the colors). Based on those 88 possibilities, I looked for repeating color patterns in this khipu. I defined a pattern, very 
much like Radicati did (Radicati di Primeglio 1964), based on the colors and color combinations that are repeated in the same pattern, on cords pertaining to the same level (secondary/subsidiary levels $1,2,3$ ). In the identification of patterns, I considered hues which are similar and could possibly be construed as the same hue; this results from the lack of a color palette to use for comparison, and from the fading of the colors.

I identified 10 patterns and two sub-patterns. The most dominant pattern is pattern no. 1: it contains more cords then any other pattern (up to 13 cords) and it is repeated in five complete clusters (excluding the secondary cords). Furthermore, some of the other patterns are related to this one. The most remarkable feature of this pattern is that is appears in the middle of the khipu (cluster 28) and at its end (cluster 95), according to the positioning of the khipu at this time.

\section{The Knots}

There are 143 cords containing knots (40 percent of the total number of cords). In this khipu, three types of knots are used: the figure-eight knot, the long knot and the simple knot. According to the decimal system as described by Locke (1923), I identified two levels of knots: one with knots which represent the units digit and the other which represents the tens digit. The figure-eight knot appears isolated on 59 cords, distributed across all levels of cords. The long knot appears isolated on 61 cords, distributed across all levels of cords. The simple knot appears isolated on six cords, distributed across all levels of cords. On three cords, the simple knot appears in clusters composed of two to five simple knots each. There are three cords that contain figure-eight knots and simple knots (one with a single simple knot, one with two simple knots, and one with three simple knots). Those cords are: a secondary cord (no. 59-0-0-0), a subsidiary cord on the first level (no. 90-7-0-0), and a subsidiary cord of the second level (no. 90-2-1-0). There are 11 cords that contain long knots and simple knots. Those cords appear on all levels except the third level of subsidiary cords.

The distance between the figure-eight knot and the point of attachment to the parent cord ranges between 16 and $32 \mathrm{~cm}$, averaging $20 \mathrm{~cm}$. The distance between the long knot and the point of attachment to the parent cord ranges from 13 to $40 \mathrm{~cm}$, averaging $21.4 \mathrm{~cm}$. The figure-eight knot and the long knot appear on the same level of the khipu cords but never on the same cord.

Urton noted that usually the figure-eight knot and the long knot do not appear on the same horizontal line even though they both record units (Urton 2003). But in the case of khipu no. 936, as well as khipu no. 935, they do appear on the same level. The distance between the simple knot and the point of attachment to the parent cord ranges between 4 to $28.5 \mathrm{~cm}$, averaging $14 \mathrm{~cm}$. There are only 14 cords which contain two levels of knots. The average distance between the 
two levels is approximately $10 \mathrm{~cm}$. As I pointed out previously in regards to the distance between the upper knot and the attachment point of the subsidiary cord, this distance is more or less the width of a hand.

Also in this case, it is interesting to note that in the first half of the khipu, the distance averages $10.7 \mathrm{~cm}$ or more, while in the second part of the khipu the distance averages $9 \mathrm{~cm}$. As Soto Flores noted in his study related to the khipus of Laramarca, the hand served as a tool for reading the knot levels (Soto Flores 1990). We may therefore assume that the hand served in the manufacturing of the khipu to measure both the distance between the knot levels, as well as the distance between the upper knot and the attachment point of the subsidiary cord. In both components, I discovered that the distance in the first half of the khipu is longer than that of the second half. If the hand of the khipu kamayuq did serve to measure this distance, this might mean that the two halves were made by different individuals.

Except for those two components I did not find any significant differences between the two halves in any other areas related to the khipu's manufacture. The sum value of knots in this khipu is 887 ; by adding the sum that appears on the $\mathrm{X}$ group (a group of cords that is currently unattached to the khipu) to this figure, it amounts to 891. In most cases, I did not find any special logic in the numerical values or in the total sum of each cluster. The sum of the knots on the secondary cords is 345 ; the first-level subsidiary cords add to 320 ; the second-level subsidiary cords add to 192; and the third-level subsidiary cords add to 30 . The sum of the $\mathrm{X}$ group is four. The highest sum of any cluster of cords occurs in cluster 90 ; it equals 355 , very close to the number of all the cords in the khipu (354, excluding the $\mathrm{X}$ group). This cluster has an unusually high sum in comparison to the other clusters; the next highest sum is 86 and it appears in cluster 9 .

I had access to three other khipus from this group: khipu no. 935 from the Maiman Collection and two other khipus, belonging to two family members of the first owner. In examining the numerical values of the knots in these khipus I did not find any numerical connection between their sums and the sums of khipu no. 936.

It seems that this khipu contains some kind of internal order based on the number four. First of all, the khipu has four levels of cords: secondary cords and subsidiary cords on three different levels. The color component has a relationship to the number four: there can be a maximum of four layers of color or color combinations in one cord (this excludes cord no. 25-0-0-0 which contains five layers; this cord is very unusual, however, due to the fact that the color changes in the middle of the knot cluster). In cords containing the spotted method of color combination, there is also a maximum of four different colors at a time. In all of these cases, the use of the fourth possibility (third-level subsidiary cord, fourth layer of color, and 
the use of four colors in the spotted method) are all rare. I could not ignore this feature, due to the fact that the number four is widely used in other aspects of the Inca culture and life.

\section{What Can be Said about Khipu No. 936? Summary and Conclusions}

After having become thoroughly acquainted with khipu no. 936 from the Maiman Collection, I sought out parallels in other samples and deal with the following questions: What can we learn from this specific sample? How should this specific khipu be classified?

There are three prominent characteristics in this khipu, which may help to clarify the answers to those questions:

1. The absence of knots in most of the khipu's cords: only 40 percent of the cords contain knots;

2. The dominant use of colors and color combinations: 75 percent of the cords contain more than one color;

3. The abundance of subsidiary cords: 73 percent of the cords are subsidiary cords.

Based on these parameters, I looked for similar samples and found three parallel khipus. The third of these is the most similar to khipu no. 936 in relation to the aforementioned characteristics.

Khipu AS57 from the Ica Museum, described by the Aschers in their databook, resembles khipu no. 936 in its small quantity of knots: approximately 35 percent of its cords contain knots. Both khipus have knots only on two decimal levels (with the exception of one cord in khipu AS57, which has three decimal levels), and most of the cords contain only one knot, generally a units knot.

Another feature common to these two khipus, which may be coincidental, is the number of cord groups. Khipu AS57 is divided into 24 groups, and khipu no. 936 has 24 clusters of subsidiary cords. Nonetheless, there are differences between the two khipus. First of all, the use of color in khipu AS57 is not as intense as in khipu no. 936. There is no use of the twisted method for color combinations in khipu AS57, and most of the latter khipu's cords contain only one color each. Furthermore subsidiary cords in khipu AS57 are rare.

Concerning the aspect of color, a parallel sample exists in the National Museum of Archaeology, Anthropology and History of Peru. This sample is currently rolled up. From the little that can be observed in photographs from Arellano's article (1999:224) on the khipu, it appears that the intense use of colors and color combinations is similar to that of khipu no. 936. Regarding other compo- 
nents, it is impossible to comment until the khipu is unrolled and we have access to further information.

A very remarkable parallel in both color components and high number of subsidiary cords is khipu no. 780 of the Chilean Museum of Pre-Columbian Art. This khipu came from Mollepamapa, in northern Chile, it was described by Urton, who named it UR35 (Urton 2001b).

As in khipu no. 936, most of the cords (around 62 percent) of khipu no. 780 have more than one color, and use the three methods of color combination described above. There are also strong parallels between the two khipus regarding the presence of subsidiary cords. Khipu no. 780 contains 88 secondary cords, and hundreds of subsidiary cords, which constitute approximately 84 percent of the khipus cords. The subsidiary cords are arranged in clusters of cords, as in the case of khipu no. 936. One difference, however, is that khipu no. 780 contains subsidiary cords up to the fifth level, whereas khipu no. 936 only contains four levels.

Regarding knots, the ratio between the two samples is inverted: while only 40 percent of khipu no. 936's cords contain knots, 60 percent of khipu no. 780's cords contain knots. Khipu no. 780 contains three decimal levels in its knots, though there are 33 cords that contain four levels of knots in which the lowest decimal level contains two units knots. This un-ignored phenomenon does not conform to the decimal system deciphered by Locke.

As Urton noted, there are khipus whose knots are formed in a similar fashion to numerical knots, but they are placed in a different position on the cord so they must represent something other than numbers. He suggests that those knots might represent signs for encoding non-numerical significance (Urton 2003).

As I previously mentioned, Marcia Ascher (2002) noted the existence of labels in the khipu. She pointed to the units knots as an indicator for classifying knots as labels; if a units knot appears anywhere except at the far end of a cord (where the units level should be), this may be a sign that the khipu contains labels or two numbers. She believes that many khipus contain both knots which symbolize labels, and knots which symbolize quantities (Ascher 1996). Considering those two observations, it is quite possible that khipu no. 780 contains some labels.

The three characteristics which I referred to above are parameters which can help me gain wider understanding of khipu no. 936. All of my interpretations are examined via those three characteristics.

\section{Could It Be a Statistical Khipu?}

The basic feature of the statistical khipu, the decimal system, also appears in khipu no. 936. As I previously mentioned, the knots are divided into two levels (units 
and tens), and the knots and the spaces between them obey the decimal system that Locke deciphered.

As I previously mentioned, knots appear on only 40 percent of the cords; the remaining 60 percent are empty of knots. But aside from lack of knots, these cords do not differ from the cords containing knots; they share the other characteristics described above, including color, spin and ply, method of attachment, etc. So what does the absence of knots tell us?

In a khipu with several decimal levels, if a cord does not have a knot in one or more of its decimal levels, this absence is interpreted as a zero. Based on this method, a total absence of knots on a cord reflects a sum of zero items in the category represented by that specific cord, rather than no mention of it altogether (Ascher 2002).

In a statistical khipu, the absence of knots in a cord might be interpreted as a debt that was paid. Salomon found some evidence for this in his study of the khipus of the community of Tupicocha. One of the community members explained to him that the absence of a knot in a cord represents a man who fulfilled all his duties to his ayllu (Salomon 2004). In the case of khipu no. 936, the implication of this hypothesis would be that 60 percent of the debts were paid off. These members of the community were mentioned in order to keep track of the structure of the social division within the khipu, even though they had already paid their debts. I can not reject this possibility, but I have some difficulty believing that a khipu was manufactured from the beginning in order to record debts the majority of which had already been paid. Yet this khipu might reflect a balance which was made at a specific moment. From my acquaintance with statistical khipus (which all express some kind of balance), I did not come across a similar absence of knots.

Colors in a statistical khipu may distinguish between different kinds of documented items. Bueno Mendoza suggests that the colorful khipu was used as a macro-state khipu (Bueno Mendoza 1990). According to this assumption, khipu no. 936, which is exceptionally colorful, might have recorded information at macrostate level. The color patterns discovered in this khipu may be interpreted as follows:

According to Bueno Mendoza's theory, we may propose that pattern 1, which is composed entirely of subsidiary cords, represents the taxes paid by various places. This would suggest, in turn, that the secondary cords that the clusters are attached to would represent the names of the places from which these taxes were collected. The pattern itself (in the subsidiary cords) may contain information about what was collected from this place or social group. The patterns might represent different categories, as described in Murra's theory (Murra 2002), or an inner order inside a category, as suggested by Pärssinen (1992). In both cases, the repetition of colors in an identical order, following a specific sequence, would be logical. Based on this logic, we can conclude that this khipu documents information on 95 different groups (represented by the 95 secondary cords of the khipu). 
Nonetheless, a difficulty arises from this suggestion, due to the fact that there are additional patterns which themselves include secondary cords; it becomes difficult to explain why some places or social groups would be mentioned more than once in the khipu.

The third parameter of khipu no. 936 is the great amount of subsidiary cords, which shaped the question about the role fulfilled by subsidiary cords. According to the Aschers, 65 percent of known khipus contain subsidiary cords. There are khipus whose subsidiary cords served for recording other numerical values, associated to the same items which were represented in their parent cords. In other khipus, some subsidiary cords might record something that is somewhat different from what was recorded in their parent cords. The Aschers suggested an additional possibility for the role of subsidiary cords; they might serve as tree diagrams, which organize information into categories and a hierarchical order (Ascher and Ascher 1997).

Combining this suggestion with Bueno Mendoza's suggestion regarding the colorful macro-state khipu, it is possible to interpret that khipu no. 936 recorded information related to tributes. The secondary cords might represent a province, while the subsidiary cords would represent villages under that province's responsibility. In this case the color would have served to identify a place, and not a number, as described by Calancha and suggested by Urton (Mann 2005). A point against this possibility, however, is the presence of the color pattern which I recognized in this khipu; it would be illogical to utilize the same signs for different locations.

Pärssinen suggested that some subsidiary cords were added to the khipu at a later stage of recording information. For example, after having recorded the basic information in the khipu, other details would be inserted on subsidiary cords attached to the related secondary cords (Pärssinen and Kivharju 2004). It is unlikely that in the case of khipu no. 936 subsidiary cords are later additions, because this would mean that most of the information in this khipu was recorded as additions.

In his study of eight khipus from this group, Zighelboim classified the khipus into two types: one is the "serial type" and the other is the "irregular type". The "serial type" refers to a khipu whose cords are divided into groups; it contains very little color, and where color is used, it is applied in the same place in each group of cords. Subsidiary cords are rare in this type of khipu. Zighelboim suggested that all serial type khipus were statistical khipu used for censuses or for recording quantities. The "irregular type" includes khipus whose cords are divided into uneven groups; they contain numerous subsidiary cords and intense color combinations, and the knots' values are small. Khipu no. 936 is clearly an "irregular type" khipu. Compared to the other 11 khipus of the group studied by Zighelboim, the sum of knots in khipu no. 936 (labeled no. 7 in his study) is unusually low (Ari Zighelboim, personal communication 2008). Other khipus from 
the group which have close to the number of cords found in this khipu, have a total value in the thousands and tens of thousands. Even khipus containing only one fourth of the number of cords in khipu no. 936 have a total value that is eight times larger.

In light of the above, I would hesitate to suggest that khipu no. 936 is a statistical khipu - It is certainly not a classic example - but it might contain some numerical information that was recorded in the decimal system.

\section{Could Khipu No. 936 Be a Calendrical Khipu?}

I cannot ignore the fact that this khipu contains 354 cords (excluding the $\mathrm{X}$ group cords), or 355 (including the missing cord in cluster no. 4), which is equal to the number of days in the lunar year. However, it is clear that this khipu was damaged and that some of its cords were ripped. In light of this fact, I can not be sure whether this khipu had 354/5 cords at its initial creation.

Even if this khipu did originally contain $354 / 5$ cords, it still contains no inner division for months as would be expected, such as in the case of the calendrical khipu from Chachapoyas, studied by Urton (2001). Nonetheless, as I mentioned earlier, the number 355 reappears in another of this khipu's features: the sum of the knots' values in cluster no. 90. From this sum, we might be able to assume that this khipu contained some astronomical information. Cluster no. 90 is exceptional, given its high number of subsidiary cords (30), as well as the abundance of knots: only six cords of these 30 cords contain no knots. As I noted before, the absence of knots is very dominant in this khipu, which makes cluster no. 90 stand out as an exception. Additionally, the color component of this cluster is distinct; it does not contain any patterns which appear in the other clusters, and even contains a unique inner pattern not seen elsewhere in the khipu. In light of the above, I would like to suggest that cluster no. 90 might contain a different type of information from the rest of the khipu. This information may well be calendrical in nature.

Another calendrical component I found in the khipu is the number of secondary cords. The chronicles' testimony demonstrates the existence of calendar reforms in Tawantinsuyu, carried out by some Inca rulers. In those reforms they tried to introduce the solar year. Montesinos mentions two types of solar year reform:

1. solar year divided into 12 months of 30 days each, with an additional short month;

2. solar year divided according to solstices and equinoxes (Szemiński 2009).

According this testimony, I cannot ignore the fact that this khipu contains 95 secondary cords, which equals a quarter of one solar year: three 30 -day months 
and five additional leap days. However, as I mentioned before, I cannot be sure that the current state of the khipu is the same as its original form.

I doubt that this khipu (excluding perhaps cluster no. 90) contains calendrical information; the absence of knots in most of the cords would make it difficult to store a large amount of numerical information. I also believe that this kind of information would not necessitate such intense use of color, which was used to document non-numerical information in all types of khipu.

I compared khipu no. 936 with khipu AS100, which according to Zuidema (1989) contains calendrical information; it does not share any physical resemblance with khipu no. 936: all of its cords (except three) contain knots, there is no use of color combinations, and there are only seven subsidiary cords on the first level. Furthermore, the cords of khipu no. 936 are not divided into groups by space or color. So if this khipu were designed to store calendrical information, it seems strange that it is not divided into groups which might represent months, as seen in khipu UR6 from Chachapoyas (Urton 2001a) or different societal groups as suggested by Zuidema (1989).

As I mentioned in the chapter on the calendrical khipu, it is assumed that the description of the $z i q^{\prime} i$ system, which was recorded in the chronicles, was originally stored in a khipu.

An explicit testimony for the storage of this kind of information in the khipu is found in the document of Juan de Matienzo, who noted that the khipu kamayuqs were interviewed about the wak'as after the conquest. There are also a few chronicle testimonies, and some archaeological evidence that prove the existence of sacred lines in communities outside of Cuzco (Bauer 2000). Considering these two observations (that the khipu recorded information about the ziq'i system, and that communities outside of Cuzco had similar systems), I will try to reconstruct how khipu no. 936 could have recorded information about a ziq'i system in the community which owned this khipu.

Rowe (1963) noted that the physical structure of the khipu is suitable for this purpose; the lines might be represented by the khipu's cords, and the wak'as might be represented by its knots. Unfortunately, Rowe's reconstruction is not suitable for this specific sample, due to the absence of knots in most of khipu's 936 cords.

Bauer (2000) demonstrated that the ziq'i of Cuzco were not necessarily straight. Keeping this in mind, it is possible that subsidiary cords represent a digression from the straight line. Another possibility is that they represent the wakas. The secondary cord might represent the $z i q^{\prime} i$, and it follows that in the case of a secondary cord with no subsidiary cords, this could represent a straight ziq'i with one wak'a.

In khipu no. 936 however, the knots cannot represent wak'as, as it is unlikely that the majority of the ziq'i contained no wak'as. Perhaps the knots represent numbers which were related to the cult of the wak'as, such as the amount of the offering, but the lack of knots in most of the cords would imply that most of the wak'as did not get offerings. A possible explanation is that, as in the case of the statistical khipu, 
the absence of knots indicates that the offering had already been given at the time the khipu was created.

In his interpretation of khipu AS100, Zuidema suggested that the khipu documented the cult obligations of six groups (Zuidema 1989). Likewise, in the testimony of Cobo about the $z i q^{\prime} i$ of Cuzco, there is a reference to the division of the cult obligations between socially related groups; each group had the responsibility to maintain one ziq'i (Bauer 2000). In light of the above, the color component of khipu no. 936 might represent the various groups that were responsible for the wakas.

According to this theory, this khipu documented 88 groups (represented by the 88 colors and colors combinations that appear in the khipu); the repetition of color patterns would imply that a few groups were responsible for more then one $z i q^{\prime} i$. In the case of the Cuzco ziq'i system, the chronicle testimonies report that each ayllu was responsible for more than one ziq'i (Bauer 2000). Due to the relatively large number of groups represented, 88 , I would like to suggest that in this case the social units are not ayllus but rather smaller groups.

There is currently no way to prove the veracity of this reconstruction of khipu no. 936. If historical and archaeological testimonies were one day unearthed which could serve as a basis for comparing the numbers of $z i q^{\prime} i$ and wak'as with the numbers of cords of this sample, this would certainly support the above interpretation.

\section{Can It Be a Non-Numerical/Narrative Khipu?}

Marcia Ascher (1996) referred to khipu AS57 (previously mentioned as an equivalent to khipu no. 936) as a khipu which recorded labels. She emphasized four components in this khipu: colored cords, absence of knots, some wrapping around a few sections of the main cord and the repetition of four single digits. Except for the wrapping sections, these components also appear in khipu no. 936, most dominantly the high number of colored cords and lack of knots.

Concerning the repetition of single digits in khipu no. 936, it is different in that it contains more than four digits, but most of the khipu knots are units knots that appear isolated on a cord. There are only 12 cords that contain exclusively tens knots, and 13 cords that contain both units and tens knots. The repetition of digits in khipu no. 936 is seen in the figure-eight knots, which appear in isolation on 41 percent of the cords containing knots; isolated units knots (two-nine) appear on another 42 percent of cords containing knots. We may assume that the similarity of those percentages is not coincidental.

More evidence for the use of the figure-eight knot as a non-numerical symbol is found in the study by Urton and Brezine about the khipus from Puruchuco. They interpreted a few of the figure-eight knots which appeared isolated on a cord as symbols representing a place that today is called Puruchuco (Mann 2005). 
According to Marcia Ascher's theory, it is possible for a khipu to contain both types of knots: knots representing quantities, as well as knots used as labels (Ascher 1996). In light of this observation I would like to suggest that khipu no. 936 is one of these khipus with dually functioning knots. Cords with only one figure-eight or units knot, as discussed above, represent labels. In this sense, cords with more than one knot (17 cords in this khipu) contain quantities, which were recorded using the decimal system. On eight of the khipu's cords, a simple knot appears in isolation; these knots might be interpreted as either labels or as quantities.

As I previously noted, khipu no. 780 from the Chilean Museum of PreColumbian Art has much in common with khipu no. 936. As I demonstrated earlier, it is possible that khipu no. 780 contains non-numerical information in the form of labels. This comparison also reinforces the idea that khipu no. 936 is one of those khipus which contain non-numerical information.

Another supporting idea is related to the dominance of color in a nonnumerical khipu, as found in the Guaman Poma testimony:

Éstos fueron hijos de apoconas [lords] secretarios de los alcaldes de corte, que prenden a los señores deste rreyno. Estos dichos secretarios onrrosos tenían quipos de colores teñidos, y se llaman quilca camayoc [specialist in qillqa - writing/drawing] o quilla uata quipoc [specialist in documenting the lunar year with knots]. Y en todo el rreyno auía escriuano de cabildo; éstos asentauan lo que pasaua en los dichos cada pueblo deste rreyno. [Guaman Poma de Ayala 2001:361].

The color component in any statistical, calendrical, or non-numerical khipu represents non-numerical information. Continuing with this observation, an intensive use of the color component implies a large amount of non-numerical information in the khipu, as in the case of khipu no. 936.

As I previously demonstrated, there are several color patterns in khipu no. 936. What could those patterns serve for in a khipu which contains narrative information? As in the case of the statistical khipu, it is possible that the narrative khipu also contained categories, which helped the khipu kamayuq to store and retrieve information from the khipu. To demonstrate this idea, I addressed the text Relación de Los Quipucamayus a Vaca de Castro which contains a summary of the information obtained from four khipu kamayuqs (Vega 1974). I used Rowe's reconstruction of the khipu that was the basis for La Memoria de las Provincias as a guide (Rowe 1985).

The text Relación de Los Quipucamayus a Vaca de Castro tells the story of the Incas; it contains an inner pattern in the way it sums up the history of each Inca. It starts with a reference to the name of the Inca, as well as his father's name. It then 
goes on to describe whether he was a good or bad ruler, and whether there was war or peace. Then it makes references to his character, to the territories he conquered (if he did conquer territories), the name of his wife, the number of sons he had from her, the name of the firstborn son, the names of the other sons and the names of their ayllus. Finally, it records how many years he ruled. This pattern is repeated in the same order throughout the text in all descriptions related to the Incas. Not all of these details appear in the summary of each Inca, but the order remains consistent. In light of this example, it is possible that the color patterns reflect the basic structure of the story, which is repeated throughout the narrative. Both in the khipu as well as in the text, there are patterns that fail to contain all the details of this basic framework. Theoretically, if we were to project the contents of this text onto khipu no. 936, the secondary cords could represent the name of the Inca, and the subsidiary cords, which constitute the pattern, could express the details of the Inca history arranged in a basic, repetitive structure.

Another possible explanation of the patterns is the Aschers' suggestion relating to formulas that served the oral tradition. They demonstrated this idea with a story that contains ten episodes in chronological order. While progressing through the story, the narrator repeats the previous episode in order to remind the audience about the tales. In a khipu, the color distinguishes between different episodes. "A narrative recorded this way would look like a number of the highly patterned, rhythmic khipus in the corpus" (Ascher 2002a:111).

Following the Aschers' suggestion regarding khipu no. 936, it is obvious that pattern no. 1 is the most dominant in the khipu. Interestingly, this pattern appears in the middle of the khipu (cluster no. 28) and at its end (cluster no. 95), assuming that there are no missing cords. Nonetheless, I could not find a systematic pattern that is rhythmically repeated throughout the khipu.

Concerning the vast number of subsidiary cords, Radicati quotes José de Acosta, who tells about an old indigenous woman who came to confession with a khipu, referred to by Acosta as "algunos hilitos". Radicati interpreted the use of the diminutive for cords as subsidiary cords; he also relied on the testimony of Garcilaso de la Vaga, who noted that subsidiary cords were thinner and split. On this basis, Radicati suggested that the secondary cords recorded the sins of this old woman, and the subsidiary cords recorded complementary information concerning her sins. He believed that a full sentence was created in this way. The subsidiary cord, according to Radicati, served as, "más que como restas de cantidades, ellas sirvieron para indicar las variaciones del contenido extranumeral de las cuerdas matrices y se emplearon para aclarar ideas y precisar conceptos" (Radicati di Primeglio 1979:91). Adding to the above, Pärssinen's theory demonstrates how it is possible to record narrative information in a khipu (Pärssinen 1992); subsidiary cords seem to have an important role in the narrative khipu. 


\section{Summary, Conclusions and Further Research}

To summarize, I doubt that khipu no. 936 is a statistical khipu. The other khipus I surveyed in this group are statistical khipus, and do not contain a single one of the parameters I pointed out. The noticeable absence of knots in khipu no. 936 makes it unlikely to assume that they are simply an indication of the debts which were paid. Furthermore, the low values of the knots do not fit a macro-state khipu (as Bueno Mendoza suggested for the colored khipu) unless those values are codes that symbolize higher values.

As I noted, khipu no. 936 contains some characteristics of the calendrical khipu, such as the number of its cords and the numerical values related to cluster no. 90. Nonetheless, the number of cords still existing today is not necessarily the number of cords that this khipu contained to begin with. Cluster no. 90 is very unusual, due to its high number of knots. It is likely to have contained other types of information that might have a calendrical nature.

The idea I proposed that khipu no. 936 recorded information about some kind of $z i q$ 'i system is a possibility, but there is no way to prove this, since there is no evidence of a $z i q^{\prime} i$ system containing the specific numbers relating to this khipu.

In light of the above, I suggest that khipu no. 936 is a khipu that contains non-numerical information, possibly including labels. Its similarities to other khipus that might contain labels (such as khipu no. AS57 and khipu no. 780 in the Chilean Museum of Pre-Colombian Art) reinforce this assumption. The khipu might, as I demonstrated, contain some numerical information in the cords that have more than one knot, or some calendrical information encoded in cluster no. 90.

I would like to offer two points for future research. The first one relates to the connection between the direction of the attachment of the subsidiaries (right or left) and the method of cord attachment (recto or verso). As I pointed out, those two have a very close correlation in khipu no. 936. The second point concerns the color patterns that I identified in this khipu. It would be interesting to examine whether these patterns appear in other khipus; this might answer some questions about the nature of those patterns.

Future research concerning khipu no. 936 would require a full study of other samples in this group, and the connections between them. I suspect that one khipu from this group (called by Zighelboim no. 11) is actually a section of a khipu no. 936; those two have much in common. Khipu no. 11 also shows an intense use of color and color combinations, an abundance of subsidiary cords, and a complete absence of knots (see Figure 2). Khipu no. 11 is not accessible to me but I would like to suggest that is actually the end part of khipu no. 936. The main cord of khipu no. 936 is ruptured at its end, and the characteristics of the main cord of khipu no. 11 are, as far 
as I can observe from the photo, very close to those of the main cord of khipu no. 936. Another point to support this suggestion relates to the attachment point of the subsidiary cords in khipu no. 11. The subsidiaries are attached very close to the main cord in khipu no. 11, while in khipu no. 936 this point of attachment is generally more distant from the main cord. The notable exceptions are clusters no. 93 and 94 (almost at the end of the khipu) in khipu no. 936, which are attached extremely close to the main cord. If khipu no. 11 was the continuation of khipu no. 936, we can see the logical connection between them in the attachment point feature. To prove this suggestion, a full study of khipu no. 11 is called for, as well as a comparison of the main cords of both khipus (no. 11 and no. 936).

Another important point for future research deals with the fact that at least two different types of khipus (the "serial" and "irregular" khipus, as Zighelboim named them) were found together in one archive. This in and of itself is very important for khipu research, and has implications concerning the definition of khipus archives. A closer examination and comparison among the "irregular" khipus of the group may reveal similarities in color patterns or other components, which might in turn lead us to a broader understanding of this type of khipu.

\section{Acknowledgments}

I would like to thank my advisor professor Jan Szemiński for his patient guidance, and Alfredo Rosenzweig, curator of the Maiman Collection, who enabled me to research and assisted me in my search and investigation on the khipu. Additional thanks to the family of the first owner of this khipu, who were kind enough to let me survey other samples of this group, in photos as well as in personal meetings. Thanks also to Ari Zighelboim who generously shared his study of this group of khipus. And finally, to my family and friends from all over (Israel, Germany, USA, Peru and Chile), thanks for your help with all of my requests.

\section{References Cited}

Arellano Hoffman, Carmen

1999 Quipu y tocapu. Sistemas de comunicación incas. In Los Incas. Arte y símbolos, edited by Franklin G. Y. Pease, Craig Morris, Julián I. Sentillana, Ramiro Matos, Paloma Carcedo de Mufarech, Luisa Vetter Parodi, Carmen Arellano, Vuka Roussakis, and Lucy Salazar, pp. 215-261. Banco de Crédito del Perú, Lima.

Ascher, Marcia

1996 Mathematical Ideas of the Incas. In Native American Mathematics, edited by Michael P. Closs, pp. 261-289. University of Texas Press, Austin.

2002 Reading Khipu: Labels, Structure, and Format. In Narrative Threads, Accounting 
and Recounting in Andean Khipu, edited by Jeffrey Quilter and Gary Urton, pp. 87-102. University of Texas Press, Austin.

Ascher, Marcia and Robert Ascher

1978 Code of the Quipu: Databook. University of Michigan Press, Ann Arbor.

1997 Mathematics of the Incas, Code of the Quipu. Dover Publications, New York.

Ascher, Robert

2002a Inka Writing. In Narrative Threads, Accounting and Recounting in Andean Khipu, edited by Jeffrey Quilter and Gary Urton, pp. 103-115. University of Texas Press, Austin.

Bauer, Brian S.

2000 El espacio sagrado de los incas. El sistema de ceques del Cuzco. Ed. Centro de Estudios Regionales Andinos "Bartolome de Las Casas”, Cuzco.

Bueno Mendoza, Alberto

1990 Hallazgo de khipu en Pachacamac. In Quipu y yupana: Colección de escritos, edited by Carol Mackey, Hugo Pereyra, Carlos Radicati, Humberto Rodríguez, and Oscar Valverde, pp. 97-104. CONCYTEC, Lima.

Guaman Poma De Ayala, Felipe

2001 [1615] El primer nueva corónica y buen gobierno. The Guaman Poma Website, The Royal Library, Copenhagen. Electronic document, http://www.kb.dk/permalink/2006/poma/info/es/foreword.htm, accessed August 8, 2010.

Makowski, Krzysztof, Alfredo Rosenzweig, and María Jésus Jiménez Díaz

2006 Weaving for the Afterlife. Peruvian Textiles from the Maiman Collection. Ampal/ Merhav, Herzliya Pituach.

Mann, Charles C.

2005 Unraveling Khipu’s Secrets. Science 309:1008-1009.

Murra, John V.

2002 El mundo andino: Población, medio ambiente y economía. Instituto de Estudios Peruanos/Pontificia Universidad Católica del Perú, Lima.

Pärssinen, Martti

1992 Tawantinsuyu: The Inca State and Its Political Organization. Studia Historica 43, Societas Historica Finlandiae, Helsinki.

Pärssinen Martti and Jukka Kiviharju

2004 Textos andinos. corpus de textos khipu incaicos y coloniales, vol. I. Instituto Iberoamericano de Finlandia and Departamento de Filología, Universidad Complutense de Madrid, Madrid.

Radicati Di Primeglio, Carlos

1964 La seriación como posible clave para descifrar los quipus extranumerales. Biblioteca de la Sociedad Peruana de Historia, Serie: Monografías VI, Universidad Nacional de San Marcos, Lima. 
1979 El sistema contable de los Incas: yupana y quipu. Librería Studium, Lima. Rowe, John H.

1963 Inca Culture at the Time of Spanish Conquest. In Handbook of South American Indians, vol. II, edited by Julian H. Steward, pp. 183-330. Cooper Square Publishers, New York.

1985 Probanza de los incas nietos de conquistadores. Histórica 9(2):193-245.

Salomon, Frank

2004 The Cord Keepers: Khipus and Cultural Life in a Peruvian Village. Duke University Press, Durham.

Soto Flores, Froilan

1990 Los kipus modernos de la localidad de Laramarca. In Quipu y yupana: Colección de escritos, edited by Carol Mackey, Hugo Pereyra, Carlos Radicati, Humberto Rodríguez, and Oscar Valverde, pp. 183-194. CONCYTEC, Lima.

Szemiński, Jan

2009 Un ejemplo de larga tradición histórica andina: "Libro 2 de las memorias antiguas historiales y políticas del Pirú" redactado por Fernando de Montesinos. Iberoamericana, Madrid.

Urton, Gary

2001a A Calendrical and Demographic Tomb Text from Northern Peru. Latin American Antiquity 12(2):127-147.

2001b Material manuscrito del estudio realizado por Gary Urton al quipu no. 780 del Museo Chileno de Arte Precolombino. Manuscript on file, Museo Chileno de Arte Precolombino, Santiago de Chile.

2003 Signs of the Inka Khipu: Binary Coding in the Andean Knotted Strings Records. University of Texas Press, Austin.

Urton, Gary and Carrie Brezine

2009 The Khipu Database Project. Electronic document, http://khipukamayuq.fas. harvard.edu/index.html, accessed August 8, 2010.

Vega, Juan J.

1974 Relación de la descendencia, gobierno y conquista de los Incas. Editorial Jurídica, Lima.

Zuidema, Tom R.

1989 A Quipu Calendar from Ica, Peru, with a Comparison to the Ceque Calendar from Cuzco. In World Archaeoastronomy. Selected Papers from the 2nd Oxford International Conference on Archaeoastronomy, edited by Anthony F. Aveni, pp. 341-351. Cambridge University Press, Cambridge. 


\section{Appendixes}

Appendix no.1. My method for describing khipu no. 936 from the Maiman Collection

My description begins with the main cord, beginning from one end and continuing lengthwise along it. I focus on the main cord's overall composition, as well as where the secondary cords are attached to it. I rely on the method used by the Aschers and by Urton.

The description starts with the secondary cord, which is the closest to the twisted extremity of the main cord, and continues toward the other end (which in this case is ruptured); this complies with the method used by the Aschers (Ascher and Ascher 1978). The description of each cord progresses from top (where it attaches to its parent cord) to bottom (the free extremity).

Khipu no. 936 has more subsidiary cords than secondary cords; most of them are part of clusters. The description of each cluster of subsidiary cords begins with the cord closest to the main cord, and continues with each cord further and further away from the main cord.

The table description starts with the number label of the cord (see Appendix no. 2 for example of the table and my codes for the khipu description). There are four columns (A, B, C and D) which compose the name of the cord when put together. Each of those columns contains a serial number, so the name contains four numbers (one for each column):

- $\quad$ the first column is titled P for pendant (also called secondary cord), and lists the secondary cord numbers for the whole khipu;

- $\quad$ the second column is titled S for subsidiary and lists the first level of subsidiary cord numbers within each cluster;

- $\quad$ the third column is titled T for third level; it lists the second level of subsidiary cord numbers within each cluster;

- $\quad$ the fourth column is titled F for the fourth level; it lists the third level of subsidiary cord numbers within each cluster.

For example the serial number 1-2-1-1 represents a third-level subsidiary cord (F); it is attached to the first cord in the second level of subsidiary cords (T), which is attached to the second first-level subsidiary cord (S), which in turn is attached to the first secondary cord $(\mathrm{P})$ of the khipu.

It is clear from this method that this khipu contains up to four levels of cords. It is also easy to recognize the level of the cord from its letter name. This is very important in khipu no. 936, because most of the cords in it are subsidiary cords. In this case, I found it less practical to use the column that the Aschers and Urton used, in which 
they registered the serial numbers of the subsidiary cords and their locations on their parent cords. Because khipu no. 936 has a large number of subsidiary cords (up to 30 subsidiary cords in a cluster), a column like this one would overly complicate the table.

The next column, E, is named "Dist.". It measures the distance (in centimeters) from the point of attachment of the cord in question, until the attachment point of its parent cord. In the case of a secondary cord, this column remains empty. Next is a column F, which I called "Length"; it records the length (in centimeters) of the cord. The next column, G, is called "Side a.. It records the side on which subsidiary cords are attached to the parent cords, either to the right or to the left of the cord. It should be noted that if viewed from the other side of the khipu, the directions would be reversed. Both left and right attachments are present in significant quantities in the khipu. In the case of secondary cords, this column remains empty. Radicati referred to this feature, but was unable to determine the kind of information stored by it. He suggested that it recorded opposite things or objects (Radicati di Primeglio 1979). The next column, $\mathrm{H}$, is named "Met. a."; it records the method of the attachment as identified by Urton "recto" or "verso": R or V (Urton 2003). Next is column $\mathrm{I}$, which is called "Spin", it refers to the spinning and plying of the cord in either an $\mathrm{S}$ form or a $\mathrm{Z}$ form. This component was added to the description method by Urton (2003). The following column, J, is called "Color \& comb", and contains information about color and color combinations. In this column, I recorded the color by codes which I created in my observation of this specific khipu, because I did have access to the ISCC-NBS designations. In order to avoid confusion, I registered the codes with numbers, thereby distinguishing them from the codes used by the Aschers and Urton. I attempted to make a parallel between my codes and the Aschers' codes (see Appendix no. 3). Each main color is designated by a number. The color's various hues are labeled by the main color's number, followed by a point and the hue's specific number. It is important to note that my coding of the colors should be considered with caution because I did not have a color table for comparing each color or hue; I coded the colors intuitively. In the case of color combinations, I employed the Ascher method, using punctuation marks, which appear between the color codes. The next column, K, "Length lay.", records the length (in centimeters) of each layer. Much of this column remains empty, as there were many cords that were not layered. I continued using the / punctuation to divide the layers. I found it more convenient to record the layer length in a separate column (unlike the Aschers and Urton), because in the case of this khipu it can be cumbersome to include all the color information in one column. The column that follows, L, is called "Knots", and contains information about the quantity of the knots, their types and their locations on the cord. I used the same method as the Aschers and Urton for encoding this information: a number, which refers to the quantity of knots of a specific type, and a letter for the type (S, L, or E). In parentheses, I recorded the length, in centimeters, from the knot until the 
point of attachment to the parent cord. The next column, M, which is called "Va.", displays the estimated value of the knot according to the decimal system of the statistical khipu, as deciphered by Locke. The following column, N, named "End", deals with the form of the lower free end of the cord. It marks whether the end of the cord is open (op), tied ( $\mathrm{kn}$ ) or ruptured (rup). The free end of a cord might be twisted or ruptured in a way that is not obvious, so it is difficult to say whether this was the form of the cord since the khipu's creation, or whether it has been damaged in some way since then. The last column, $\mathrm{O}$, is named "Com", and was adopted from Urton's table. This column registers comments: if there is an asterisk, I have included a comment about the cord.

Appendix no.2. An example of the description:

Table of khipu no. 936 from the Maiman Collection

\section{The Abbreviations for Column Titles}

Dist. $=$ Distance from the connection

Length $=$ Length of the cord

Side $\mathrm{a} .=$ Side of the attachment

Met. a. $=$ Method of the attachment

Spin $=$ Spinning and plying of the cord

Color \& comb. $=$ Color and color combination

Length lay. $=$ Length of the layers

Va. = Estimated value

End $=$ End of cord

\section{The Abbreviations of the Columns' Contents}

In the "Side a." column:

$\mathrm{L}=$ left

$\mathrm{r}=$ right (I used the small letter for distinguishing from the capital $\mathrm{R}$ of the next column)

In the "Met. a." column:

$\mathrm{R}=$ recto

$\mathrm{V}=$ verso

In the "Spin" column:

$S=$ the $S$ form

$\mathrm{Z}=$ the $\mathrm{Z}$ form

In the "Knots" column:

$\mathrm{S}=$ Simple knot

$\mathrm{E}=$ Figure-eight knot

L (following a number from 2-9) = Long knot 


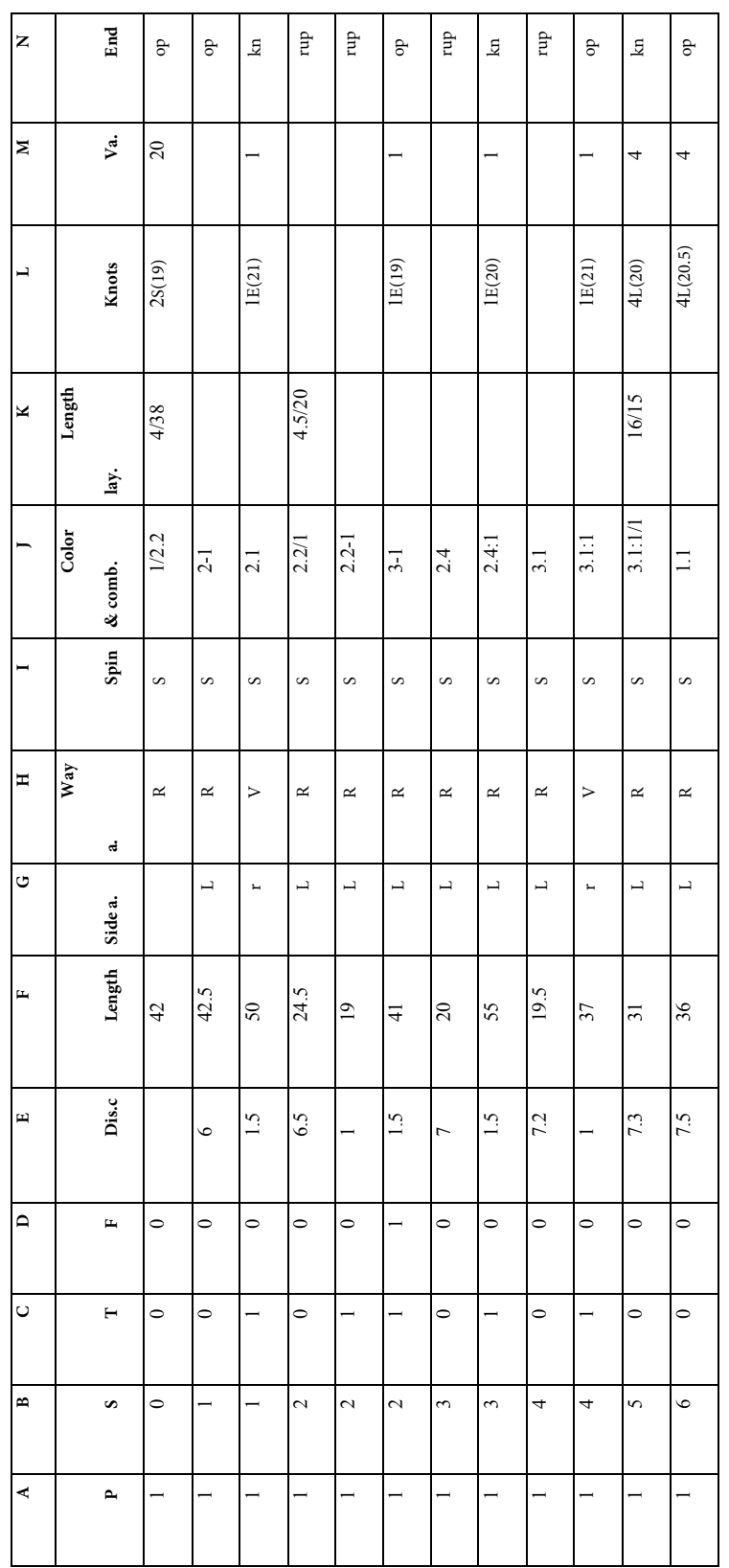

Table 1. Table of khipu no. 936 from the Maiman Collection. 


\section{Bat-ami Artzi}

In the "End" column:

op $=$ Open

$\mathrm{kn}=$ Knotted

rup $=$ Ruptured

Appendix no.3. My color codes compared with the Aschers' color codes.

\begin{tabular}{|c|c|c|}
\hline $\begin{array}{l}\text { Aschers' color codes } \\
\text { (Ascher and Ascher 1978) }\end{array}$ & English name of the color & My color codes \\
\hline \multirow[t]{2}{*}{$\mathrm{W}$} & White & 1 \\
\hline & Beige & 1.1 \\
\hline $56(\mathrm{DB})$ & Dark brown & 2 \\
\hline \multirow[t]{4}{*}{$57(\mathrm{AB})$} & Light brown & 2.1 \\
\hline & Faded brown & 2.2 \\
\hline & Blackish brown & 2.3 \\
\hline & Mocha & 2.4 \\
\hline \multirow[t]{3}{*}{$42(\mathrm{RL})$} & Light reddish brown & 2.5 \\
\hline & Dark blue & 3 \\
\hline & Faded blue & 3.1 \\
\hline \multirow[t]{2}{*}{$185(\mathrm{BL})$} & Pale blue & 3.2 \\
\hline & Khaki blue & 3.3 \\
\hline $186(\mathrm{BG})$ & Grayish blue & 3.4 \\
\hline $113(\mathrm{GY})$ & Khaki & 4 \\
\hline $127(\mathrm{G})$ & Light khaki & 4.1 \\
\hline $267(\mathrm{LK})$ & Black & 5 \\
\hline $265(\mathrm{MG})$ & Gray & 6 \\
\hline
\end{tabular}

